\title{
Clinical characteristics and value in early reperfusion therapy for new onset right bundle branch block in patients with acute myocardial infarction
}

\author{
JINGCHAO LI ${ }^{1}$, XIAODONG LI ${ }^{2}$, SHUJUAN DONG ${ }^{1}$, YAPAN YANG ${ }^{1}$ and YINGJIE CHU ${ }^{1}$ \\ Departments of ${ }^{1}$ Cardiology and ${ }^{2}$ Radiology, Henan Provincial People's Hospital, Zhengzhou, Henan 450003, P.R. China
}

Received February 15, 2017; Accepted September 20, 2017

DOI: 10.3892/etm.2017.5661

\begin{abstract}
The value of the right bundle branch block (RBBB) in the treatment of acute myocardial infarction remains unclear. Studies on the RBBB may significantly influence the treatment of acute myocardial infarction. A total of 845 patients with acute myocardial infarction who underwent primary coronary angiography at Henan Provincial People's Hospital were analyzed. Higher peak enzyme levels, a higher ratio of Killip $\geq$ II and closer proximal occlusion of infarct-related artery (IRA) were observed in patients with RBBB compared with those without. The ratio of TIMI flow 0/1 of IRA and ratio of received primary percutaneous coronary intervention (PCI) to IRA in the RBBB group were significantly higher compared with those in the left (L) BBB or no BBB groups. The in-hospital major adverse cardiac events (MACE) incidence in the RBBB group was higher compared with that in the no BBB group, but there was no significant difference between the RBBB and $\mathrm{LBBB}$ groups. Logistic regression revealed that proximal occlusion and TIMI flow $0 / 1$ of IRA were predictive factors of $\mathrm{RBBB}$. Cox regression analysis identified $\mathrm{RBBB}$ [risk ratio $(\mathrm{RR}), 4.682 ; \mathrm{P}<0.001$ ] and $\mathrm{LBBB}$ (RR, 3.687; $\mathrm{P}<0.001)$ as independent predictors of in-hospital MACE. The cumulative one-year survival rate in the RBBB group was significantly lower than those in the no BBB group $(\mathrm{P}<0.05)$ and the LBBB group $(\mathrm{P}<0.05)$. Similar to the guidelines regarding new onset of $\mathrm{LBBB}$, new onset $\mathrm{RBBB}$ should be considered as a standard indicator for reperfusion therapy; as RBBB is associated with more severe symptoms, and higher incidents of complete occlusion of IRA and primary PCI treatment compared with LBBB.
\end{abstract}

Correspondence to: Dr Yingjie Chu, Department of Cardiology, Henan Provincial People's Hospital, 7 Weiwu Road, Zhengzhou, Henan 450003, P.R. China

E-mail: hnqbdsl@126.com

Key words: acute myocardial infarction, right bundle branch block, revascularization, indication for reperfusion therapy

\section{Introduction}

The cardiovascular disease is one of major diseases threatening human health, among which acute myocardial infarction (AMI) posses a higher incidence rate when compared with other diseases in China even the whole world as well, and it features rapid onset, fast development and high mortality due to life-threatening severe arrhythmia and cardiogenic shock. Myocardial infarction (MI) is ischemic necrosis of cardiac muscle. Based on coronary artery disease, MI manifests a drastic reduction or suspension of the coronary artery blood supply, which causes severely and lastingly acute ischemia of corresponding cardiac muscle, thus leading to myocardial necrosis $(1,2)$. Current literatures showed that bundle branch block (BBB) often expressed by wide infarct size. The rate of cardiac failure, malignant arrhythmia and fatality has been increasing significantly; therefore, more and more attentions have been paid to BBB's clinical significance (3-5).

Recent study (6) showed that MI will cause myocardial ischemia or infarct which may affect the conducting system of heart, and it always results in various heart blocks, among which the occurrence rate of the right bundle branch block (RBBB) reaches $10-13 \%$. Foreign documents (7) indicated that the occurrence rate of AMI patients with left bundle branch block (LBBB) was $3.2 \%$. Though the incidence rate of AMI patients with $\mathrm{LBBB}$ is lower than that with RBBB, it has been increasing over these years. Thus it has been a hot issue to study BBB on AMI patients' prognosis. Studies showed that there was a higher mortality in patients with AMI combined with LBBB or RBBB than those without bundle-branch block (8), therefore, the bundle-branch block simultaneously with AMI had significant meaning for the symptoms and prognosis of AMI patients.

Previous researches showed that the mortality of patients with AMI combined with LBBB or RBBB was higher than that of patients with NBBB; however, current notable guidelines of AMI treatment only recommended new onset LBBB as the indication for reperfusion therapy since 1996 (9-11). Our studying team had repeatedly questioned above phenomena since 2010 (12-14) aiming at exploring the clinical characteristics and value in early reperfusion therapy of new onset RBBB in patients with acute myocardial infarction further, and providing evidence for the treatment of AMI patients with RBBB. 


\section{Patients and methods}

Patients. A total of 845 patients with AMI subjected to primary coronary angiographic in Henan Provincial People's Hospital (Zhengzhou, China) from January 2008 to June 2016 were analyzed retrospectively according to the diagnostic criteria of AMI (15) as proposed by ACC/AHA/ESC. The patient whose document was incomplete and prospective life time was shorter than one year was excluded. According to the appearance of ECG in $12 \mathrm{~h}$ after onset of symptom, these patients were divided into three groups: RBBB, LBBBB and non-bundle branch block (non-BBB). The patients with bifascicular block were excluded. Ultimately, 845 patients were included in our study. The Ethics Committee and all the patients agreed to the study as they are patients in Henan Provincial People's Hospital. All the experimental processes were carried out as per the standards of the Ethics Committee.

Data collections. Data of patients' baselines characteristics were recorded on the admission data on electrocardiographic findings, and the coronary angiographic findings were documented (Table I). The diagnosis of in-hospital MACE and in-hospital mortality were recorded. The diagnostic criteria of the left and right bundle-branch block were all in line with the standards of bundle-branch block recommended in AHA/ACCF/HRS guideline for electrocardiogram 2009 (16).

LBBB: i) QRS duration is $\geq 120 \mathrm{msec}$; ii) broad notched or slurred R wave in leads I, aVL, V5 and V6 as well as an occasional RS pattern in V5 and V6 attributed to displaced transition of QRS complex; iii) absent q waves in leads I, V5, and V6, but in the lead aVL, a narrow q wave may be present in the absence of myocardial pathology; iv) R peak time is greater than $60 \mathrm{msec}$ in leads V5 and V6 but normal in leads V1, V2 and V3, when small initial $r$ waves can be discerned in the above leads; v) ST and T waves usually opposite in direction to QRS; vi) positive $\mathrm{T}$ wave in leads with upright QRS may be normal (positive concordance); vii) depressed ST segment and/or negative $\mathrm{T}$ wave in leads with negative QRS (negative concordance) are abnormal.

RBBB: i) QRS duration is $\geq 120$ msec in adults; ii) rsr', rsR', or rSR' in leads $\mathrm{V} 1$ or $\mathrm{V} 2$. The $\mathrm{R}^{\prime}$ or $\mathrm{r}^{\prime}$ deflection is usually wider than the initial $\mathrm{R}$ wave. In a minority of patients, a wide and often notched $\mathrm{R}$ wave pattern may be seen in lead V1 and/or V2; iii) the duration of $\mathrm{S}$ wave is greater than $\mathrm{R}$ wave or greater than $40 \mathrm{msec}$ in leads I and V6; iv) normal R peak time in leads V5 and V6 but $>50 \mathrm{msec}$ in lead V1. Of the above criteria, the first three should be present to make the diagnosis. When a pure dominant $\mathrm{R}$ wave with or without a notch is presented in V1, criterion 4 should be satisfied.

MACE: Including cardiac death, re-infraction, acute left heart failure/ deterioration of heart function, cardiac shock, malignant arrhythmia (e.g., three-degree atrioventricular block, ventricular fibrillation and sustained ventricular tachycardia).

Statistical analysis. All the data were analyzed using SPSS 23.0 software (SPSS, Inc., Tokyo, Japan). Absolute numbers, percentages, means and SD, median, and upper/lower quartile were computed as appropriate. Categorical variables were compared by using the $\chi^{2}$ or Fisher exact test, as appropriate, and the odds ratio (OR) and the $95 \%$ confidence intervals were calculated. Independent predictors of new onset RBBB, LBBB, peak level of creatine kinase-MB (CK-MB), level of heart function and occluded position of IRA in AMI patients were screened by Logistic regression stepwise method. Independent predictors of MACE during hospitalization were analyzed by $\mathrm{COX}$ regression proportional hazard model. $\mathrm{P}<0.05$ was considered to indicate a statistically significant difference. The survival rate was analyzed by Kaplan-Meier method.

\section{Results}

Difference of clinical baselines characteristics. Seventy patients $(8.28 \%)$ presented RBBB and $56(6.63 \%)$ patients presented LBBB in 845 patients with AMI, as shown in Table I. Compared with non-BBB patients, RBBB patients had a higher incidence of smoking, hypertension and diabetes, hyperlipidaemia, worse heart function and higher peak enzyme level $(\mathrm{P}<0.05)$. Compared with LBBB patients, the RBBB patients were almost male, and have a lower incidence of smoking, hypertension and diabetes, and a lower peak enzyme level $(\mathrm{P}<0.05)$. The heart function between $\mathrm{LBBB}$ and $\mathrm{RBBB}$ had no significant difference $(\mathrm{P}>0.05)$.

Coronary angiographic (CAG) findings and percutaneous coronary intervention (PCI) stent implantation. All of the 845 patients received emergent CAG. The distribution of IRA between RBBB and non-BBB group had obvious difference (Table II). IRA was anterior descending artery (LAD) in $54.29 \%$ of $\mathrm{RBBB}$ patients and $35.47 \%$ in $\mathrm{LBBB}$ patients (54.29 vs. $35.47 \%, \mathrm{P}<0.001$ ). $35.47 \%$ of RBBB patients' IRA was right coronary artery (RCA); however, there was no statistical significance in the difference of IRA's distribution between RBBB patients and LBBB patients. The incidence of complete occluded IRA was higher in RBBB patients than that in non-BBB patients $(88.57$ vs. $52.16 \%)(\mathrm{P}<0.05)$ and $\mathrm{LBBB}$ patients $(88.57$ vs. $62.50 \%)(\mathrm{P}<0.05)$. The ratio of IRA occluded position in proximal vessel of RBBB patients is noticeably higher than that of non-BBB patients (74.29 vs. $19.33 \%)(\mathrm{P}<0.05)$, and also higher than that of LBBB patients but without statistical significance. The Acceptance rate of emergency PCI patients in RBBB group was prominently higher than that in non-BBB group (87.14 vs. $66.20 \%)$ $(\mathrm{P}<0.05)$ and that in LBBB group $(55.36$ vs. 87.14\%) $(\mathrm{P}<0.05)$.

Electrocardiographic (ECG) findings. By analyzing ECG of all patients, we found that the distribution of infarct sites had obvious difference between RBBB group and non-BBB group $(\mathrm{P}<0.05)$ and difference also existed between $\mathrm{RBBB}$ group and $\mathrm{LBBB}$ group $(\mathrm{P}<0.05)$. The anterior and high lateral wall myocardial infarction (58.57\%) was common in RBBB group, followed by the inferior wall and the right ventricular myocardial infarction (34.29\%) (Table III). In this research, the graphics characteristic of RBBB in 10 patients $(14.29 \%)$ in RBBB group and in 5 patients $(8.93 \%)$ in LBBB group appeared in hyperacute period, but the difference of ratio between the two groups had no statistical significance.

Independent predictor of new onset $R B B B$. After inducting the clinical baselines characteristics and CAG findings (such as age, sex, underlying disease, IRA and occluded position of IRA) 
Table I. Patients baseline characteristics.

\begin{tabular}{|c|c|c|c|c|c|}
\hline \multirow[b]{2}{*}{ Characteristics } & \multirow{2}{*}{$\begin{array}{c}\text { New RBBB } \\
(\mathrm{n}=70)\end{array}$} & \multirow{2}{*}{$\begin{array}{c}\text { No BBB } \\
(n=719)\end{array}$} & \multirow{2}{*}{$\begin{array}{c}\text { New LBBB } \\
\quad(\mathrm{n}=56)\end{array}$} & \multicolumn{2}{|c|}{ P-value } \\
\hline & & & & $\mathrm{P}_{1}$ & $\mathrm{P}_{2}$ \\
\hline Mean age (years) & $66.50 \pm 17.80$ & $61.25 \pm 11.73$ & $64.58 \pm 19.24$ & 0.102 & 0.158 \\
\hline Sex (males, \%) & $52(74.29)$ & $552(76.77)$ & $29(51.79)$ & 0.658 & $0.015^{\mathrm{a}}$ \\
\hline Smoking (\%) & $57(81.43)$ & $455(63.28)$ & $32(57.14)$ & $0.002^{\mathrm{a}}$ & $0.003^{\mathrm{a}}$ \\
\hline Hypertension (\%) & $51(72.86)$ & $362(50.35)$ & $41(73.21)$ & $<0.001^{\mathrm{a}}$ & 1.000 \\
\hline Diabetes (\%) & $35(50.00)$ & $229(31.85)$ & $31(55.36)$ & $0.003^{\mathrm{a}}$ & 0.593 \\
\hline Hyperlipemia (\%) & $16(22.86)$ & $64(8.90)$ & $15(26.79)$ & $0.001^{\mathrm{a}}$ & 0.679 \\
\hline Killip $\geq 2(\%)$ & $55(78.57)$ & $205(28.51)$ & $46(82.14)$ & $<0.001^{\mathrm{a}}$ & 0.659 \\
\hline Peak level of CK-MB & $560.00 \pm 356.74$ & $214.23 \pm 187.25$ & $630.85 \pm 465.89$ & $0.001^{\mathrm{a}}$ & $0.023^{\mathrm{a}}$ \\
\hline Symptom to balloon time (h) & $6.14 \pm 3.25$ & $4.12 \pm 3.87$ & $5.69 \pm 3.54$ & 0.352 & 0.8491 \\
\hline
\end{tabular}

$\mathrm{P}_{1}$-value applies to the comparison of RBBB vs. No BBB. $\mathrm{P}_{2}$-value applies to the comparison of LBBB vs. New RBBB. RBBB, right bundle branch block; LBBB, left BBB; CK-MB, creatine kinase-MB. ${ }^{\mathrm{a}} \mathrm{P}<0.05$, indicating a significant difference.

Table II. Angiographic findings and reperfusion therapy.

\begin{tabular}{|c|c|c|c|c|c|}
\hline \multirow[b]{2}{*}{ Variables } & \multirow[b]{2}{*}{$\begin{array}{c}\text { New RBBB } \\
(\mathrm{n}=70)\end{array}$} & \multirow[b]{2}{*}{$\begin{array}{l}\text { No BBB } \\
(n=719)\end{array}$} & \multirow{2}{*}{$\begin{array}{c}\text { New LBBB } \\
\quad(\mathrm{n}=56)\end{array}$} & \multicolumn{2}{|c|}{ P-value } \\
\hline & & & & $\mathrm{P}_{1}$ & $\mathrm{P}_{2}$ \\
\hline $1-\mathrm{VD}(\%)$ & $10(14.29)$ & $164(22.81)$ & $8(14.29)$ & 0.218 & 0.635 \\
\hline $2-\mathrm{VD}(\%)$ & $22(31.43)$ & $161(22.39)$ & $10(17.86)$ & & \\
\hline $3-\mathrm{VD}(\%)$ & $43(61.43)$ & $462(64.26)$ & $43(76.79)$ & & \\
\hline IRA-LMCA (\%) & $3(4.29)$ & $54(7.51)$ & $5(8.93)$ & $<0.001^{\mathrm{a}}$ & 0.215 \\
\hline IRA-LAD (\%) & $38(54.29)$ & $255(35.47)$ & $24(42.86)$ & & \\
\hline IRA-LCX (\%) & $6(8.57)$ & $260(36.16)$ & $11(19.64)$ & & \\
\hline IRA-RCX (\%) & $27(38.57)$ & $184(25.59)$ & $18(32.14)$ & & \\
\hline Proximal lesion of IRA (\%) & $52(74.29)$ & $139(19.33)$ & $35(62.50)$ & $<0.001^{\mathrm{a}}$ & 0.1235 \\
\hline Proximal lesion-LAD (\%) & $29(41.43)$ & $54(7.51)$ & $12(21.43)$ & & \\
\hline Proximal lesion-LCX (\%) & $2(2.86)$ & $27(3.76)$ & $7(12.50)$ & & \\
\hline Proximal lesion-RCX (\%) & $19(27.14)$ & $29(4.03)$ & $10(17.86)$ & & \\
\hline $\mathrm{TIMI}=0 / 1(\%)$ & $62(88.57)$ & $375(52.16)$ & $35(62.50)$ & $<0.001^{\mathrm{a}}$ & $0.0351^{\mathrm{a}}$ \\
\hline PCI (\%) & $61(87.14)$ & $476(66.20)$ & $31(55.36)$ & $0.009^{\mathrm{a}}$ & $0.005^{\mathrm{a}}$ \\
\hline
\end{tabular}

into the logistic equation, we found that the TIM $0 / 1$ of IRA $(\mathrm{OR}=3.28, \mathrm{P}<0.01)$ and proximal occlusion of IRA $(\mathrm{OR}=12.72$, $\mathrm{P}<0.01)$ were independent predictors of the new onset $\mathrm{RBBB}$.

In-hospital prognosis. There were 217 cases of in-hospital MACE among the 845 patients, 41 cases in RBBB group, 146 cases in non-BBB group and 30 cases in LBBB group. The $\mathrm{RBBB}$ group was significantly different with the non-BBB group in aspect of the average days of stay, left ventricular ejection fraction, pro-BNP, heart failure, cardiac shock, cardiovascular mortality and the total rate of MACE $(\mathrm{P}<0.05)$; but there was no obvious difference between RBBB group and LBBB group
$(\mathrm{P}>0.05)$ (Table IV). The grade of heart function, peak level of CK-MB, new onset of RBBB, new onset of LBBB and the occluded position of IRA were independently associated with the appearance of in-hospital MACE in the multivariate Cox proportional hazard regression model (Table V). The new RBBB had a RR value of 4.682 for the in-hospital MACE event, indicated that the probability of a MACE incident occurring in patients with AMI associated with a new RBBB is 4.682 times higher than that in patients without RBBB.

One-year mortality comparison. According to one-year Kaplan-Meier survival analysis, the cumulative one-year survival 
Table III. Position of infarctions.

\begin{tabular}{|c|c|c|c|c|c|}
\hline \multirow[b]{2}{*}{ Variables } & \multirow{2}{*}{$\begin{array}{c}\text { New RBBB } \\
\quad(n=70)\end{array}$} & \multirow{2}{*}{$\begin{array}{l}\text { No BBB } \\
(n=719)\end{array}$} & \multirow{2}{*}{$\begin{array}{c}\text { New LBBB } \\
\quad(n=56)\end{array}$} & \multicolumn{2}{|c|}{ P-value } \\
\hline & & & & $\mathrm{P}_{1}$ & $\mathrm{P}_{2}$ \\
\hline Anterior and/or high-lateral wall (\%) & $41(58.57)$ & $369(51.32)$ & $31(55.36)$ & $<0.001^{\mathrm{a}}$ & $0.032^{\mathrm{a}}$ \\
\hline Inferior and/or posterior wall (\%) & $3(4.29)$ & $240(33.38)$ & $16(28.57)$ & & \\
\hline Inferior and/or right ventricular (\%) & $24(34.29)$ & $102(14.19)$ & $8(14.29)$ & & \\
\hline
\end{tabular}

$\mathrm{P}_{1}$-value applies to the comparison of RBBB vs. No BBB. $\mathrm{P}_{2}$-value applies to the comparison of LBBB vs. New RBBB. RBBB, right bundle branch block; LBBB, left BBB. ${ }^{a} \mathrm{P}<0.05$, indicating a significant difference.

Table IV. In-hospital outcomes.

\begin{tabular}{|c|c|c|c|c|c|}
\hline \multirow[b]{2}{*}{ Variables } & \multirow{2}{*}{$\begin{array}{c}\text { New RBBB } \\
n=70\end{array}$} & \multirow{2}{*}{$\begin{array}{c}\text { No BBB } \\
n=719\end{array}$} & \multirow{2}{*}{$\begin{array}{c}\text { New LBBB } \\
n=56\end{array}$} & \multicolumn{2}{|c|}{$\mathrm{P}$-value } \\
\hline & & & & $\mathrm{P}_{1}$ & $\mathrm{P}_{2}$ \\
\hline Mean in-hospital time (day) & $20.06 \pm 8.50$ & $10.23 \pm 5.69$ & $18.46 \pm 10.87$ & $0.012^{\mathrm{a}}$ & 0.985 \\
\hline Mean EF (\%) & $43.59 \pm 17.86$ & $64.71 \pm 27.51$ & $42.18 \pm 23.42$ & $0.041^{\mathrm{a}}$ & 0.756 \\
\hline Pro-BNP (pg/ml) & $2,320 \pm 1983$ & $265 \pm 238$ & $2,579 \pm 1652$ & $<0.001^{\mathrm{a}}$ & 0.521 \\
\hline Heart failure $(\%)$ & $10(14.28)$ & $15(2.09)$ & $7(12.50)$ & $<0.001^{\mathrm{a}}$ & 0.800 \\
\hline Malignant arrhythmia (n, \%) & $9(12.86)$ & $36(5.00)$ & $5(8.93)$ & $0.013^{\mathrm{a}}$ & 0.576 \\
\hline Auricular fibrillation (n, \%) & $5(7.14)$ & $33(4.59)$ & $4(7.14)$ & 0.373 & 1.000 \\
\hline Cardiogenic shock $(\mathrm{n}, \%)$ & $11(15.71)$ & $37(5.15)$ & $6(10.71)$ & $0.002^{\mathrm{a}}$ & 0.446 \\
\hline Cardic death $(\mathrm{n}, \%)$ & $13(18.57)$ & $36(5.00)$ & $10(17.86)$ & $<0.001^{\mathrm{a}}$ & 1.000 \\
\hline All MACE (n, \%) & $41(58.57)$ & $146(20.36)$ & $30(53.57)$ & $<0.001^{\mathrm{a}}$ & 0.169 \\
\hline
\end{tabular}

$\mathrm{P}_{1}$ is the comparison between the New RBBB and No BBB groups, and the $\mathrm{P}_{2}$ is the comparison between the New RBBB and New LBBB groups. ${ }^{a} \mathrm{P}<0.05$, indicating a significant difference. $\mathrm{RBBB}$, right bundle branch block; LBBB, left BBB; MACE, major adverse cardiac events .

Table V. Independent predictors of in-hospital MACE (adjusting other factors).

\begin{tabular}{|c|c|c|c|c|}
\hline Variables & Coefficient & P-value & $\mathrm{RR}$ & $95 \% \mathrm{CI}$ \\
\hline Peak level of CK-MB & 0.009 & $0.012^{\mathrm{a}}$ & 2.035 & $0.825-1.689$ \\
\hline Level of heart function & 3.021 & $<0.001^{\mathrm{a}}$ & 41.283 & $1.382-373.468$ \\
\hline New RBBB & 1.897 & $<0.001^{\mathrm{a}}$ & 4.682 & $1.025-8.567$ \\
\hline New LBBB & 1.123 & $<0.001^{\mathrm{a}}$ & 3.687 & $1.002-6.589$ \\
\hline Occluded position of IRA & 1.259 & $0.038^{\mathrm{a}}$ & 2.037 & $1.258-8.593$ \\
\hline
\end{tabular}

RBBB, right bundle branch block; LBBB, left BBB; CI, confidence interval; MACE, major adverse cardiac events; CK-MB, creatine kinase-MB . ${ }^{\mathrm{a}} \mathrm{P}<0.05$, indicating a significant difference.

rate in $\mathrm{RBBB}$ group was significantly different with that in the no $\mathrm{BBB}$ group $(\mathrm{P}=0.046)$. Also, compared with the LBBB group, the $\mathrm{RBBB}$ group had a lower survival rate, and the difference was statistically significant $(\mathrm{P}<0.001 ;$ Fig. 1$)$.

\section{Discussion}

The high mortality of AMI combined with bundle branch block was confirmed in the 1970s (1); however, authoritative guidelines for AMI all over the world only recommend new onset LBBB as an indication of reperfusion therapy but never mention the new onset RBBB.

Previous reports about AMI combined with new onset RBBB showed that the incidence of new RBBB in AMI was 4-18\%. The research results showed that the incidence of new RBBB in AMI patients in the first $12 \mathrm{~h}$ was $6.32 \%$, slightly higher than the incidence in the reports of Wagner et al (17) and Widimsky et al (18), and also higher than the incidence 


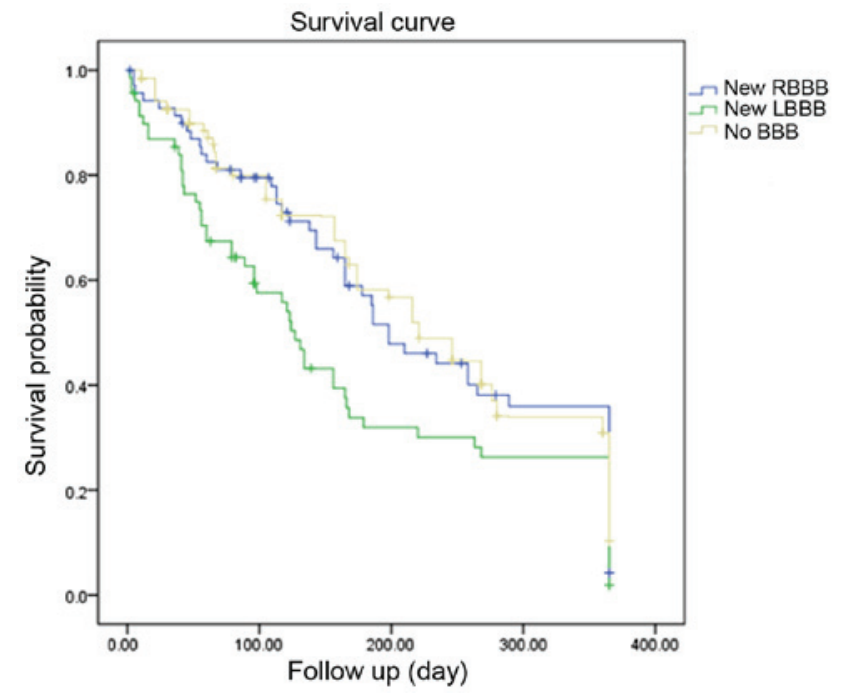

Figure 1. Comparison of survival rates between patients with RBBB, LBBB or no BBB. RBBB, right bundle branch block; LBBB, left BBB.

of new LBBB in this research. There was no obvious difference in the peak level of CK-MB, the level of heart function, the incidence of in-hospital MACE and in-hospital mortality between RBBB group and LBBB group; but all indexes in the former two groups were higher than those in the non-BBB group. The above results are similar to previous documentations (4). In RBBB group, the ratio of that IRA was LAD was $54.29 \%$ and the ratio of that IRA was RCX was $38.57 \%$. Both of the above percentages were higher than those in non-BBB group significantly but had no apparent difference in contrast with those in LBBB group. The right bundle branch is slender and runs through inter-ventricular septum. The blood supply of proximal end of right bundle branch comes from inter-ventricular septal anterior artery and atrioventricular nodal artery, while the middle and distal end of right bundle branch are supplied by penetrating branches from the left anterior descending coronary artery independently. Thus, occlusion of the LAD is associated with the appearance of new RBBB; however, LBBB which has strong anti-ischemia ability accepts double blood supply from LAD and the posterior descending branch (19). The incidence of new RBBB in AMI patients is higher than that of new LBBB; moreover, this research also showed that the proportion of anterior and/or high lateral wall myocardial infarction as induced by LAD occlusion in AMI combined with new RBBB patient was high. This finding can be supported by previous research (17).

The right coronary artery supplies $90 \%$ of the upper portion of the inter-ventricular septum, including the AV node, the bundle of His and the upper segments of the two main bundle branches (20). In this sense, the occlusion of RCX can not only induce disturbance of $\mathrm{AV}$ conduction but also lead to bundle branch block (21). In 1976, Fukuda et al (22) reported that the interruption of blood flow at the proximal right coronary artery could result in the right ventricular dilatation. Chronic damage of RBBB in combination with mechanical stretching might be the main reasons for the appearance of new RBBB. In this clinic research, we found that rate of new RBBB was $38.57 \%$ in RBBB patients with occlusion of RCX. Further analyses indicated that the proportion of proximal occlusion and TIMI $0 / 1$ of IRA was higher in RBBB group than that in non-BBB group obviously.

The complete occlusion of RCX can obstruct the blood supplement of the right ventricular branch which originates from RCX. Because of disappearance of right ventricular branch's blood supplement, a large area of the right ventricular myocardial ischemia can induce the maximum rate of depolarization of 0 phase to slow down. As a result, the conduction velocity of activation in the right ventricular myocardium slows down, thus the left and right ventricular depolarization is not synchronous, which may contribute to the incidence of MACE.

The findings of this research also showed that the proportion of proximal occlusion of IRA in RBBB group was obviously higher than that in non-BBB group; but there was no significant difference between RBBB group and LBBB group. The proportions of TIMI 0/1 in IRA and patients conducted primary PCI in RBBB group were both higher than those in the non-BBBB group and the LBBB group. These results illustrated that the characteristics of coronary of AMI patients combined with new onset RBBB were more accordant with the indication of primary PCI. Additionally, further logistic regression analysis showed that the proximal occlusion and TIMI flow 0/1 of IRA were both the independent risk factors of new onset RBBB in AMI patients. COX regression analysis showed that new onset RBBB was an independent predictor of in-hospital MACE, the same as new onset LBBB.

The characteristic of coronary lesion of AMI in combination with the new onset RBBB is proximal complete occlusion of LAD or RCX. The essential reason of the appearance of new onset RBBB in AMI patients are blood supply obstruction of the right bundle branch and the ischemia or necrosis of a large area in the right ventricular myocardium. As to these patients, clinical symptoms are more serious and the prognosis is worse; therefore, the demand of reperfusion therapy is more urgent; however, at present, the majority guidelines regarding to the indications of emergency revascularization in AMI only mention the elevation of ST segment and the new or presumed new LBBB all over the world (9-11). Our team has been proposing the query at the absence of RBBB in these guidelines of AMI since 2010 (12-14). Widimsky et al (18) proposed the recommendation that new onset RBBB should be included in the indications of emergency revascularization in AMI European patients. This research confirmed that AMI patients with new onset RBBB was a group which existed objectively. In addition, the incidence of new RBBB was higher than new LBBB in AMI patient and the characteristic of coronary lesion in new RBBB patients was fitter the indication of primary PCI than LBBB and non-BBB patients. The reasons mentioned above corroborate that new onset $\mathrm{RBBB}$ in AMI should be listed as indication of emergency revascularization as new onset LBBB. In fact, both the guidelines of the American College of Emergency Physicians for the management of patients with suspected AMI or unstable angina in 2000 (23) contained this standpoint but not attracted serious concerns.

Currently, the reason supporting the guidelines which exclude the new onset RBBB is that LBBB influences the first $40 \mathrm{msec}$ of the ventricular depolarization and hide the appearance of pathological Q wave, hereby further affecting 
the diagnosis of AMI; however, RBBB only influences the last $40 \mathrm{msec}$ of ventricular depolarization without effect on AMI diagnosis. We consider further researches are needed to explore early phase indicator prompting ischemic. Pathological Q wave is the electrocardiographic characteristic of establishing the phase rather than hyperacute or evolving phase. Thus, early revascularization cannot be accomplished by depending on the pathological Q waves in AMI patients. In this research, the incidence of new RBBB in the first $12 \mathrm{~h}$ since symptom onset was higher than new LBBB, and 4 cases of new RBBB were detected in hyperacute phase in RBBB group. In addition, the detection rate of new $\mathrm{RBBB}$ in hyperacute phase had no obvious difference when compared with the new LBBB's. Apparently, the value of new onset RBBB in early diagnosis and revascularization shouldn't be ignored; moreover, if the new onset RBBB was excluded from the indications of emergency revascularization in these authoritative guidelines of AMI, these guidelines would not only transmit the error information that AMI patients combining with new RBBB were few and the symptom of these patients was not severe, but also manifest the defect of theoretical system of electrocardiogram.

Bansilal et al (24) in their long-term follow-up found that AMI patients with LBBB had increasing possibility of adverse cardiovascular events including death, sudden death and revascularization. In this study, the one-year cumulative survival in RBBB group was obviously lower than that in non-BBB group and their inter-difference was statistically significant. Study by Kleemann et al (25) demonstrated that AMI patients with RBBB had poor prognosis and low long-term survival. Studies on AMI patients with $\mathrm{LBBB}$ or with RBBB indicated that those patients had wild infarct size and high rate of adverse cardiovascular events. Longer follow-up might conduct more accurate results, which still demanded retrospective analyses on a large scale and for long-term.

In-time unblocking of infarcted vessel can improve the patients' prognosis. Some study indicated that, with all contraindications being excluded, AMI patients with BBB should receive emergency PCI treatment (26). Though thrombolysis can effectively decrease AMI patients' mortality and features advantage of massive utility, easy implementation and low coast, thrombolysis therapy has more contraindications and higher risk of bleeding; as a result, PCI treatment is more popular at present; moreover, research by Keeley (27) showed that it would be better for AMI patients to conduct emergency PCI treatment than thrombolysis therapy.

The primary limitation of this study is retrospective characteristics. We cannot determine the onset time of RBBB in numbers of the acute myocardial infarction patients, thus presumable RBBB may influence the statistical result of the research. Another limitation in relation to the fact is that the coronary angiography analysis was not performed in a blinded manner.

The characteristic of coronary artery lesion of most acute myocardial infarction patients accompanying with new onset RBBB is completely proximal occlusion of LAD or RCX. Compared with non-BBB patients, the peak level of CK-MB, the level of heart function and the incidence of in-hospital MACE are higher in the new onset RBBB patients. The incidence of in-hospital MACE and detection rate in hyperacute phase between LBBB group and RBBB has no obvious difference, but the incidence of new onset $\mathrm{RBBB}$ is higher than the new LBBB in acute myocardial infarction patients. Thus, the new onset RBBB should be considered as indication of emergency revascularization in the guidelines of acute myocardial infarction.

\section{Acknowledgements}

I thank all authors who have contributed to this study for advice and comments. This study is supported by Research on Revascularization of Chinese patients with acute coronary syndromes, attached to Key Project of Science of Technology Department of Henan Province in 2012 (grant no. 122102310068).

\section{References}

1. Ross JC and Dunning AJ: Right bundle branch block and left axis deviation in acute myocard-ialinfarction. Br Heart $\mathrm{J} 32$ : 847-851, 1970 .

2. Nguyen BL, Tufano F, De Angelis S, Tersigni F, Alessandri N and Brugada P: Ventricular fibrillation induction and diffuse abnormal ST-segment response to ajmaline in a patient with apparent pre-existing dynamic right bundle branch block. Eur Rev Med Pharmacol Sci 18: 3115-3119, 2014.

3. Freedman RA, Alderman EL, Sheffield LT, Saporito M and Fisher LD: Bundle branch block in patients with chronic coronary artery disease: Angiographic correlates and prognostic significance. J Am Coll Cardiol 10: 73-80, 1987.

4. Melgarejo-Moreno A, Galcerá-Tomás J, Garciá-Alberola A, Valdés-Chavarri M, Castillo-Soria FJ, Mira-Sánchez E, Gil-Sánchez J and Allegue-Gallego J: Incidence, clinical characteristics, and prognostic significance of right bundle-branch block in acute myocardial infarction: A study in the thrombolytic era. Circulation 96: 1139-1144, 1997.

5. Wagdy HM, Hodge D, Christian TF, Miller TD and Gibbons RJ: Prognostic value of vasodilator myocardial perfusion imaging in patients with left bundle-branch block. Circulation 97: 1563-1570, 1998 .

6. Patanè S, Marte F, Di Bella G and Chiribiri A: Atrial fibrillation with intermittent right axis deviation in the presence of complete left bundle branch block. Int J Cardiol 129: e1-e2, 2008.

7. De Sutter J, De Bondt P, Van de Wiele C, Fonteyne W, Dierckx R, Clement D and Tavernier R: Prevalence of potential candidates for biventricular pacing among patients with known coronary artery disease: A prospective registry from a single center. Pacing Clin Electrophysiol 23: 1718-1721, 2000.

8. De Sutter J: Incidence of potential candidates for biventricular pacing in heart failure: Results from a one year single-centre prospective registry. Eur Heart J 21: 192, 2000.

9. Wong CK, Stewart RA, Gao W, French JK, Raffel C and White HD: Prognostic differences between different types of bundle branch block during the early phase of acute myocardial infarction: Insights from the Hirulog and Early Reperfusion or Occlusion (HERO)-2 trial. Eur Heart J 27: 21-28, 2006.

10. Ryan TJ, Anderson JL, Antman EM, Braniff BA, Brooks NH, Califf RM, Hillis LD, Hiratzka LF, Rapaport E, Riegel BJ, et al: ACC/AHA guidelines for the management of patients with acute myocardial infarction: Executive summary. A report of the Amer-ican College of Cardiology/American Heart Association Task Force on Practice Guidelines (Committee on Management of Acute Myocardial Infarction). Circulation 94: 2341-2350, 1996.

11. Antman EM, Anbe DT, Armstrong PW, Bates ER, Green LA, Hand M, Hochman JS, Krumholz HM, Kushner FG, Lamas GA, et al: American College of Cardiology. American Heart Association. ACC/AHA guidelines for the management of patients with ST-elevation myocardial infarction-executive summary: A report of the American College of Cardiology/American Heart Association Task Force on Practice Guidelines (Writing Committee to revise the 1999 guidelines for the management of patients with acute myocardial infarction. J Am Coll Cardiol 44: 671-719, 2004. 
12. Task Force on the management of ST-segment elevation acute myocardial infarction of the European Society of Cardiology (ESC)1, Steg PG, James SK, Atar D, Badano LP Blömstrom-Lundqvist C, Borger MA, Di Mario C, Dickstein K, Ducrocq G, et al: ESC Guidelines for the management of acute myocardial infarction in patients presenting with ST-segment elevation. Eur Heart J 33: 2569-2619, 2012.

13. Chu YJ: New thinking of acute myocardial infraction electrocardiogram. J Prac Diag Therap 24: 533-536, 2010.

14. Iwasaki J, Kono K, Katayama Y, Takahashi N, Takeuchi K, Tanakaya M, Osawa K, Shiraki T and Saito D: Prognostic significance of right bundle branch block in patients with acute inferior myocardial infarction. Acta Med Okayama 63: 25-33, 2009.

15. Chu YJ, Wang FF, Liu XY, HE WQ and Wang YH: Several rare changes in the electro-cardiogram with myocardial ischemia. Chin J Card Pacing Electro Physio 25: 330-333, 2011.

16. ThygesenK,AlpenJS and WhiteHD;JointESC/ACCF/AHA/WHF Task Force for the Redefinition of Myocardial Infarction: Universal definition of myocardial infarction. J Am Coll Cardiol 50: 2173-2195, 2007.

17. Wagner GS, Macfarlane P, Wellens H, Josephson M, Gorgels A, Mirvis DM, Pahlm O, Surawicz B, Kligfield P, Childers R, et al: AHA/ACCF/HRS recommendations for the standardization and interpretation of the electrocardiogram: part VI: acute ischemia/infarction: a scientific statement from the American Heart Association Electrocardiography and Arrhythmias Committee, Council on Clinical Cardiology; the American College of Cardiology Foundation; and the Heart Rhythm Society. Endorsed by the International Society for Computerized Electrocardiology. J Am Coll Cardiol 53: 1003-1011, 2009.

18. Widimsky P, Rohác F, Stásek J, Kala P, Rokyta R, Kuzmanov B, Jakl M, Poloczek M, Kanovsky J, Bernat I, et al: Primary angioplasty in acute myocardial infarction with right bundle branch block: Should new onset right bundle branch block be added to future guidelines as an indication for reperfusion therapy? Eur Heart J 33: 86-95, 2012.
19. Brilakis ES, Wright RS, Kopecky SL, Reeder GS, Williams BA and Miller WL: Bundle branch block as a predictor of long-term survival after acute myocardial infarction. Am J Cardiol 88: 205-209, 2001

20. Hadziselimovic H: Vascularization of the conducting system in the human heart. Acta Anat 102: 105-110, 1978.

21. James TN and Burch GE: Blood supply of the human interventricular septum. Circulation 17: 391-396, 1958.

22. Fukuda K, Nakata Y, Okada R and Takagi T: Histopathological studies on the conduction susytem of complete right bundle branch block wth special reference to configuration of QRS complex. Jpn Heart J 20: 831-844, 1979.

23. American College of Emergency Physicians: Clinical policy: Critical issues in the evaluation and managent of adult patients presenting with suspected acute myocardial infarction or unstable angina. Ann Emerg Med 35: 521-544, 2000.

24. Bansilal S, Aneja A, Mathew V, Reeder GS, Smars PA, Lennon RJ, Wiste HJ, Traverse K and Farkouh ME: Long-term cardiovascular outcomes in patients with angina pectoris presenting with bundle branch block. Am J Cardiol 107: $1565-1570,2011$

25. Kleemann T, Juenger C, Gitt AK, Schiele R, Schneider S, Senges J, Darius H and Seidl K; MITRA PLUS Study Group: Incidence and clinical impact of right bundle branch block in patients with acute myocardial infarction: ST elevation myocardial infarction versus non-ST elevation myocardial infarction. Am Heart J 156: 256-261, 2008.

26. Gallagher EJ: Which patients with suspected myocardial ischemia and left bundle-branch block should receive thrombolytic agents? Ann Emerg Med 37: 439-444, 2001.

27. Keeley EC, Boura JA and Grines CL: Primary angioplasty versus intravenous thrombolytic therapy for acute myocardial infarction: A quantitative review of 23 randomised trials. Lancet 361: 13-20, 2003. 